\title{
ANTIFUNGAL ACTIVITY OF PIMENTA DIOICA (L.) MERRIL AN AROMATIC MEDICINAL TREE
}

\author{
AKHILESH BHAT, RAVEESHA K. A.* \\ Centre for Innovative Studies in Herbal Drug Technology, Department of Studies in Botany, University of Mysore, Manasagangotri, \\ Mysore 570026 \\ Email: karaveesha@gmail.com
}

Received: 17 Nov 2015 Revised and Accepted: 12 Aug 2016

\begin{abstract}
Objective: To assess the antifungal activities of the extracts of leaves of Pimenta dioica against human pathogenic fungi and identify the class of phytochemical responsible for the biological activity.

Methods: The shade dried, and powdered leaves of Pimenta dioica were subjected to polarity based solvent extraction by soaking. The extracts were dried in a rotary flash evaporator and subjected to antifungal activity assay against Candida albicans, Microsporum canis and M. gypseum, by disc diffusion method. Antifungal active petroleum ether extract was subjected to phytochemical analysis to identify the active compound. The extract was then subjected to Thin Layer Chromatography (TLC) and Bioautography, by agar overlay method. The fractions were collected by Preparative TLC method and subjected to antifungal activity assay by disc diffusion method. Further, the Libermann-Burchard test was conducted to detect the broad group of compounds responsible for the bioactivity.
\end{abstract}

Results: Among the five extracts viz. petroleum ether, chloroform, ethyl acetate, methanol and aqueous, the petroleum ether extract showed significant antifungal activity against Microsporum canis (50 mm), Microsporum gypseum (60 mm) and Candida albicans (23 mm). Terpenoids, tannins and flavonoids were found to be the chief constituents of the petroleum ether extract. The TLC of the extract revealed 7 spots with the Rf values $0.37,0.42,0.45,0.52,0.59,0.76,0.96$ with the solvent system of hexane and acetone (1:0.5). The bioautography assay revealed inhibitory activity in the spots at Rf values 0.52 and 0.59 . These fractions obtained by preparative TLC also confirmed the same. The phytochemical analysis of the fractions on the TLC plate suggests that the compound is triterpene or steroid.

Conclusion: The antifungal activity of Pimenta dioica and the bioactive phytochemical has been reported in the present study. Preliminary phytochemical analysis has indicated that the compounds are triterpenes or steroids. The results indicate that the active compounds are potential lead molecules for new antifungal drugs in the management of infectious fungi.

Keywords: Pimenta dioica, Leaf extract, Terpenoids, Bioautogrpahy, Antifungal activity, Microsporum, Candida

(C) 2016 The Authors. Published by Innovare Academic Sciences Pvt Ltd. This is an open access article under the CC BY license (http://creativecommons. org/licenses/by/4. 0/) DOI: http://dx.doi.org/10.22159/ijpps.2016v8i10.9924

\section{INTRODUCTION}

History is replete with references to human infectious diseases, which have altered its course. At the same time, man has also been in a constant quest for effective medicines against these diseases. Preparations of medicinal plant parts were some of the earliest therapeutics employed. Many of these preparations were preserved in writing and are available to this day.

However, some of the medicinal uses of plants are not recorded in literature, but the knowledge has been passed through generations of healers in the various indigenous communities. All these knowledge sources are an important resource in the development of new drugs to combat infectious diseases.

Among the various infectious diseases afflicting humans, the diseases caused by fungi are very difficult to cure and require a prolonged duration of treatment. They are a significant cause of morbidity and mortality in immunocompromised patients who includes patients with AIDS, cancer and those with organ transplants [1]. Fungal diseases in humans can be either subcutaneous or systemic. The present study focuses on fungi, which are primarily subcutaneous.

The existing treatment for fungal diseases comprises of a class of steroidal drugs named "Azole drugs". Therapeutic options for treatment are limited, and most of these drugs have similar modes of action. Further, these steroidal drugs are known to possess a number of side effects and present problems of toxicity over prolonged treatment durations. Furthermore, most treatments are not capable of completely eradicating the fungus from the infected individual's body [2, 3]. Discovering new antifungal agents with potent activity and low toxicity is the need of the hour.
In this context, plants can be exploited for discovering biomolecules with therapeutic potential against human disease-causing fungi. The plants generally used in traditional health care are known to possess a wide array of bioactive molecules with low or limited side effects. It may also be recalled that plants are the chief source of biomolecules for therapeutic drugs; as much as $40 \%$ of all known drugs are either directly sourced from plants or the derivatives of plant biomolecules [4].

The aim of the study was to analyze the antifungal potential of the extracts of the leaves of the aromatic tree Pimenta dioica (L.) Merril. It is an exotic plant whose fruits are used as a spice and its aroma and flavour is a mix of Clove, Cinnamon and Nutmeg. Hence it is commonly referred as "allspice".

Allspice or Pimenta dioica is small-sized tree belonging to the family Myrtaceae. It is a small tree, about 8-10 m tall with smooth, peeling bark. The leaves are oppositely arranged, petiolate, with narrowly elliptic or oblong blades having abundant oil glands and strong, spicy odor when crushed. They are dioecious; flowers are borne in axillary panicles; sepals are distinct in bud; petals and stamens are white colored. The fresh fruits are green, with purple-black colour on ripening; two seeds are found in each fruit [5].

The essential oils of the leaves and fruits of this plant are anesthetic, analgesic, antimicrobial, antioxidant, antiseptic, acaricidal, carminative, muscle relaxant, rubefacient, and stimulant. It is also used as a tonic for several digestive tract problems like cramps, flatulence, indigestion and nausea. Further, its essential oils are used in medicines to treat cases of depression, nervous exhaustion, tension, neuralgia and stress. Commercially, the leaf and fruit oil is used in perfumery, aftershaves and food flavorings [6-8]. Since the plant is widely used in traditional medicine as antimicrobial and 
antiseptic, it has been selected for scientific validation in the present study.

\section{MATERIALS AND METHODS}

\section{Test plant}

The leaves of $P$. dioica were collected from a fully grown tree in a farm at Maratikyathanahalli, Mysore. It was identified by an expert taxonomist of Department of Studies in Botany, and a herbarium specimen is deposited in the herbarium of the Department of Studies in Botany, University of Mysore. The leaves were washed with running tap water; shade dried, powdered and sealed and stored at $4^{\circ} \mathrm{C}$ until used.

\section{Preparation of plant extracts}

The dried leaf powder was extracted successively with increasingly polar solvents viz. petroleum ether, chloroform, ethyl acetate, methanol (Thermo Fischer Scientific, Mumbai) and water. $100 \mathrm{~g}$ of the leaf powder was soaked in $200 \mathrm{ml}$ of the solvent for $24 \mathrm{~h}$ and filtered through Whatman No.1 filter paper (Whatman International Ltd., Maidstone, England). The filtrate was dried in a rotary flash evaporator (IKA-RV10) and the dried extract was stored at $4{ }^{\circ} \mathrm{C}$ until further use [9].

\section{Test fungi}

Candia albicans (yeast) (MTCC183), Microsporum canis (MTCC2820) and Microsporum gypseum (MTCC2830) (dermatophytes) were selected as test organisms for the present study. The test fungi were procured from Microbial Type Culture Collection Centre (MTCC), Institute of Microbial Technology, Chandigarh the organisms were maintained on Sabourad's Dextrose Agar (SDA) (HiMedia, Mumbai).

\section{Antifungal activity assay}

The antifungal activity assay of aqueous extracts was done by agarwell diffusion method [10] and that of the solvent extracts was done by disc diffusion method [11]. Twenty-four hours old culture of $C$. albicans and ten-day old cultures of dermatophytes grown in Sabourad's Dextrose Broth (SDB) were taken as inoculum for the assays. Miconazole (HiMedia, Mumbai) was employed as a positive control. The concentration of the solvent extracts and the positive control was $10 \mathrm{mg} / \mathrm{ml}$ and $50 \mu \mathrm{l}$ was added to each disc. $100 \mu \mathrm{l}$ of the aqueous extracts was added to the agar wells. Negative control was maintained by taking the respective solvents used for the preparation of the extracts. Three replicates were maintained.

\section{Statistical analysis}

The results of the antifungal activity assays were statistically analyzed by using the software SPSS (Software Package for Social Sciences) ver.20 (IBM Corp., Armonk, New York). The data was subjected to One-Way ANOVA (Analysis of Variance) and Tukey's HSD (Highest Significant Difference) at $\mathrm{P}<0.05$.

\section{Phytochemical analysis}

The preliminary phytochemical analysis of the petroleum ether extract of the leaves of $P$. dioica was done to identify the broad groups of phytochemicals present in the extract. The tests were carried out according to the procedures outlined by Trease and Evans, Sofowora, and Harborne [12-14].

\section{Thin layer chromatography}

The petroleum ether extract of the leaves of $P$. dioica, which showed significant antifungal activity, was subjected to TLC to separate the phytochemicals in it. Various combinations of the polar and non-polar solvents were tried to determine the best solvent system to achieve a clear separation of the bands. The Retention factor (Rf) values of the separated bands was calculated by using the formula:

$$
\mathrm{Rf}=\frac{\text { Distance travelled by the solute }}{\text { Distance travelled by the solvent }}
$$

\section{Bioautography}

The agar overlay method was used to conduct the bioautography assay to localize the antifungal compound on the TLC plate after separation. TLC was carried out on silica gel-250-GF pre-coated aluminium plates (Merck KGaA, Darmstadt, Germany) of $7 \mathrm{~cm} \times 2 \mathrm{~cm}$ dimensions. The plates were kept under UV light for sterilization and then placed on the lower lid of sterile petriplates. SDB with $0.7 \%$ $\mathrm{w} / \mathrm{v}$ agar medium inoculated with the test fungi was poured carefully on the TLC plates. The plates were sealed and incubated at $35 \pm 2{ }^{\circ} \mathrm{C}$ for $48 \mathrm{~h}[3]$.

\section{Phytochemical analysis of the TLC spots 0.52 and 0.59}

After separation of the compounds in the petroleum ether extract by TLC, the TLC plates were sprayed with modified LiebermannBurchard reagent $(1 \mathrm{ml}$ conc. Sulphuric acid $+20 \mathrm{ml}$ Acetic anhydride $+25 \mathrm{ml}$ Chloroform) and placed in an oven at $85-90{ }^{\circ} \mathrm{C}$ for $15 \min [14]$.

\section{RESULTS}

\section{Antifungal activity assay}

The antifungal activity assay (table 1 ) indicated a strong antifungal effect in the petroleum ether extract of the leaves of $P$. dioica. The diameters of the zone of inhibition against the test fungi were 23 $\mathrm{mm}, 50 \mathrm{~mm}$ and $60 \mathrm{~mm}$ against $C$. albicans, M. canis and M. gypseum respectively. The activity was comparable to that of the positive control Miconazole.

The chloroform extract also had some inhibitory effect on all the test fungi with zone sizes ranging from $20 \mathrm{~mm}$ to $40 \mathrm{~mm}$. The methanol extract showed mild inhibition of the growth of the dermatophytes.

Table 1: Antifungal activity of the extracts of leaves of Pimenta dioica against human pathogenic fungi

\begin{tabular}{llll}
\hline \multirow{2}{*}{ Extract } & \multicolumn{2}{l}{ Diameter of the zone of Inhibition (mm) } & \\
\cline { 2 - 4 } & Candida albicans & Microsporum canis & Microsporum gypseum \\
\hline Petroleum ether & $23.3 \pm 0.33^{\mathrm{c}}$ & $50.3 \pm 0.33^{\mathrm{e}}$ & $59.6 \pm 0.33^{\mathrm{d}}$ \\
Chloroform & $19.3 \pm 0.33^{\mathrm{b}}$ & $19.6 \pm 0.33^{\mathrm{c}}$ & $39.6 \pm 0.33^{\mathrm{c}}$ \\
Ethyl Acetate & $0 \pm 0.0^{\mathrm{a}}$ & $0 \pm 0.0^{\mathrm{a}}$ & $0 \pm 0.0^{\mathrm{a}}$ \\
Methanol & $0 \pm 0.0^{\mathrm{a}}$ & $13.3 \pm 0.33^{\mathrm{b}}$ & $10.3 \pm 0.33^{\mathrm{b}}$ \\
Water & $0 \pm 0.0^{\mathrm{a}}$ & $0 \pm 0.0^{\mathrm{a}}$ & $0 \pm 0.0^{\mathrm{a}}$ \\
Miconazole $50 \mu \mathrm{g},($ Positive control) & $23.6 \pm 0.33^{\mathrm{c}}$ & $39.6 \pm 0.33^{\mathrm{d}}$ & $40.3 \pm 0.33^{\mathrm{c}}$ \\
\hline
\end{tabular}

Note: Concentration of the test extracts is $0.1 \mathrm{~g} / \mathrm{ml}$, All values are mean $\pm \mathrm{SE}$ of triplicates. The values with different superscripts are significantly different from one another at $\mathrm{P}<0.05$ (Tukey's HSD).

The statistical analysis of the results of the antifungal activity assay revealed that the activity of petroleum ether extract was significantly higher than that of the positive control (miconazole) against M. canis and M. gypseum and comparable with it in the case of $C$. albicans.

\section{Phytochemical analysis}

The results of the phytochemical analysis are presented in table 2 . The broad groups of phytochemicals present in the petroleum ether extract of the leaves of $P$. dioica are terpenoids, steroids, coumarins, tannins and flavonoids. 
Table 2: The phytochemical analysis of the petroleum ether extract of the leaves of $P$. dioica

\begin{tabular}{ll}
\hline Phytochemical & Presence/absence \\
\hline Carbohydrates & -- \\
Proteins and amino acids & -- \\
Phenols & -- \\
Tannins & + \\
Saponins & -- \\
Phlobatannins & -- \\
Alkaloids & -- \\
Flavonoids & + \\
Terpenoids & + \\
Steroids & + \\
Cardiac Glycosides & -- \\
Glycosides & -- \\
Carotenoids & -- \\
Coumarins & + \\
Anthraquinones & -- \\
\hline
\end{tabular}

Note: “+” indicates presence, “--” indicates absence

\section{Thin layer chromatography}

The petroleum ether extract of $P$. dioica showed the presence of seven bands when subjected to TLC with the solvent system comprising of hexane and acetone in the ratio 1: 0.5 . The Rf values of the bands were calculated, and they were as follows: $0.37,0.42,0.45$, $0.52,0.59,0.76,0.96$ (fig. 1).

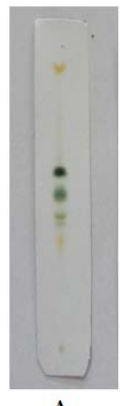

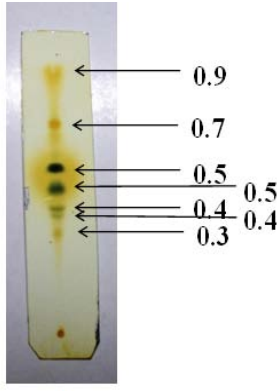

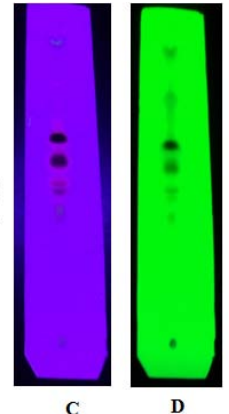

C
Fig. 1: Thin layer chromatography of the petroleum ether extract of $P$. dioica. A. under visible light, B. after treatment with iodine vapour, C. under long UV light (365 nm), D. under short UV light (254 nm)

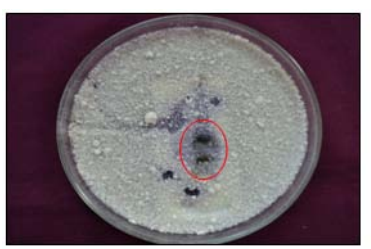

$\mathbf{A}$

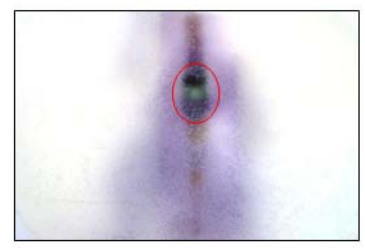

C

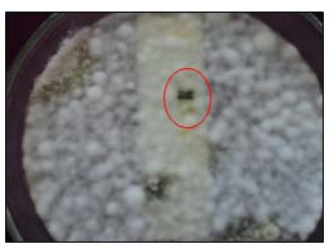

B

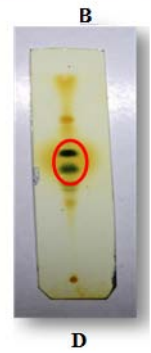

D
Fig. 2: Bioautography of the petroleum ether extract of $P$. dioica against test fungi. A. Microsporum canis, B. Microsporum gypseum, C. Candida albicans, D. TLC plate with the active spots marked

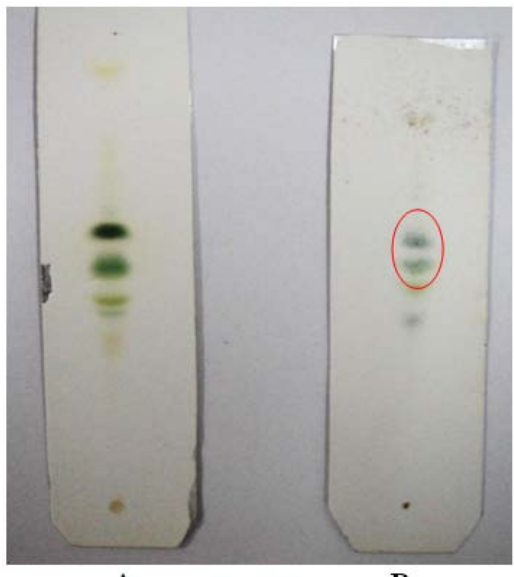

A

B

Fig. 3: The Phytochemical analysis of the TLC spots 0.52 and 0.59. A. TLC of the Petroleum ether extract, B. Plate sprayed with reagent showing violet spots at $\mathrm{Rf} 0.52$ and 0.59

\section{Bioautography}

The bioautography of the petroleum ether extract of $P$. dioica showed small clear zones around the TLC spots at Rf 0.52 and 0.59 (fig. 2) against all the three test fungi. It indicated that the antifungal compounds are present at the above-mentioned positions on the TLC plates. However, further separation would be needed to characterize the compounds and assess their potency in inhibiting the growth of the test fungi.

\section{Phytochemical analysis of the TLC spots 0.52 and 0.59}

The TLC plates sprayed with modified Liebermann-Burchard reagent showed a change in the colour of the spots from dark green to bluish-green indicating the presence of triterpenes/steroids.

\section{DISCUSSION}

The study analyses the potential of the extracts of the leaves of $P$. dioica in inhibiting the growth of selected human pathogenic fungi; the phytochemical analysis of the petroleum ether extract which showed the highest antifungal activity and separation and localization of the bioactive compounds by TLC and bioautography.

Reports on the pharmacological activities, particularly antimicrobial antioxidant and tumoricidal activity of different parts of the plant are available in the literature, and a few bioactive compounds have been isolated and characterized. Al-Rehaily et al. [15] conducted studies on the pharmacological properties of the aqueous suspension of fruits of $P$. dioica for anti-inflammatory, analgesic, antipyretic, gastric antiulcer, and cytoprotective activities in experimental models. Their studies showed that the extract had anti-inflammatory, cytoprotective and antiulcer activities. More importantly, toxicity studies showed neither mortality nor adverse effects up to a dose of $7.5 \mathrm{~g} / \mathrm{kg}$ in mice. Thus the study established that $P$. dioica fruit extracts may be less toxic and effective therapeutically.

Lai and Roy [16] reviewed the existing literature of that time on the antimicrobial and chemopreventive properties of some commonly used herbs and spices, including $P$. dioica. They have collected data of reported activities against mycotoxigenic Aspergillus, Shigella sonnei and Shigella flexneri, Salmonella entiritica and Listeria monocytogens. Eugenol was found to be the most widely attributed active compound from these studies.

The chemical composition of the essential oil extracted from the leaves of $P$. dioica from Jamaica was analyzed by GC and GC-MS [8]. Eugenol (76.02\%), methyl eugenol (7.14\%) and $\beta$-caryophyllene $(6.47 \%)$ were found to be the major constituents.

The antimicrobial activity of essential oil of $P$. dioica and other spices was evaluated against spoilage and pathogenic microorganisms isolated from 
meat products, which included many bacteria such as Staphylococcus aureus, Pseudomonas aeruginosa, Escherichia coli, etc., along with the yeast Candida albicans [17]. The essential oil of $P$. dioica showed significant activity against all the test microorganisms. The workers attributed the activity of the oil to its eugenol content.

Zabka et al. [18] assessed the antifungal activity of essential oils of 25 medicinal plants, including that of $P$. dioica, against two species each of Fusarium, Penicillium and Aspergillus. The essential oil of $P$. dioica showed $100 \%$ inhibition of mycelial growth of all the test fungi. Further, the Minimal Inhibitory Concentration of the oil was reported in the range of $0.5-0.7 \mu \mathrm{l} / \mathrm{ml}$. They also analyzed the essential oil by GC-MS and found that it was comprised of a number of compounds of which the major ones were eugenol, methyl eugenol, and $\beta$-caryophyllene. From the literature survey, it is evident that the present study is the first report on the antifungal activity of the extracts of the leaves of $P$. dioica against human pathogenic fungi. The activity of the petroleum ether extract was comparable to that of the standard antifungal drug Miconazole. This opens up the possibility of isolating and characterizing bioactive compounds possessing antifungal action against these pathogens. The test fungi used for the study are the cause of a large number of illnesses like thrush, Candidiasis, Tinea corpis and many other skin infections. Most of these are difficult to eradicate and have prolonged treatment durations with associated toxicities of the existing antifungal drugs. Hence new drug from a plant source could be a source of novel, effective and less toxic curative.

\section{CONCLUSION}

The study has analyzed the antifungal potential of the extracts of the leaves of Pimenta dioica, and it was found to have significant activity against the test human pathogenic fungi comprising of yeast and dermatophyte forms. The petroleum ether extract which was subjected to phytochemical analysis, TLC and bioautography revealed that the extract possessed steroids/triterpenes as the active constituents. Further studies are needed to identify and characterize the structure of the bioactive compound responsible for the antifungal activity. The study has laid the foundation for discovering a potent phytochemical with possibly lower side effects to treat human fungal infections.

\section{ACKNOWLEDGEMENT}

The authors wish to acknowledge the financial support provided by the Institution of Excellence program of the University of Mysore (MHRD-UGC) and the Vision Group of Science and Technology, Govt. of Karnataka.

\section{CONFLICT OF INTERESTS}

\section{Declared none}

\section{REFERENCES}

1. Fisher-Hoch SP, Hutwagner L. Opportunistic candidiasis; an epidemic of the 1980's. Clin Infect Dis 1995;21:897-904.
2. Sheehan DJ, Hoelscher AC, Sibley MC. Current and emerging azole antifungal agents. Clin Microbiol Rev 1999;12:40-79.

3. Masoko P, Eloff JN. The diversity of antifungal compounds of six South African Terminalia species (Combretaceae) determined by bioautography. Afr J Biotech 2005;4:1425-31.

4. Newman DJ, Cragg GM, Snader KM. Natural products as sources of new drugs over the period 1981-2002. J Nat Prod 2003;66:1022-37.

5. Wagner WL, Herbst DR, Sohmer SH. Manual of the flowering plants of Hawaii. 2 vols. Honolulu: Bishop Museum Special Publication; 1999.

6. Seidemann J. World Spice Plants. Heidelberg: Springer Verlag; 2005. p. 286-7.

7. Sharma R. Medicinal plants of India. An encyclopedia. New Delhi: Daya Publishing House; 2003.

8. Jirovetz L, Buchbauer G, Stoilova I, Krastanov A, Stoyanova A, Schmidt E. Spice plants: chemical composition and antioxidant properties of Pimenta Lindl. essential oils, part 1: Pimenta dioica (L.) Merr. leaf oil from Jamaica. Nutrition 2007;31:55-63.

9. Dabur R, Gupta A, Mandal TK, Singh DD, Bajpai V, Gurav AM, et al. Antimicrobial activity of some Indian medicinal plants. Afr J Tradit Complementary Altern Med 2007;4:313-8.

10. Cos P, Vlietinck A, Berghe DV, Maes L. Anti-infective potential of natural products: how to develop a stronger in vitro 'proof-ofconcept'. J Ethnopharmacol 2006;106:290-302.

11. Bauer AW, Kirby WM, Sherris JC, Turck M. Antibiotic susceptibility testing by a standardized single disk method. Am J Clin Pathol 1966;45:493-6.

12. Trease GE, Evans WC. Pharmacognosy. 11 $11^{\text {th }}$ ed. London: Bailliere Tindall; 1989.

13. Sofowora A. Medicinal plants and traditional medicine in Africa. Ibadan, Nigeria: Spectrum Books Ltd; 1993. p. 191-289.

14. Harborne JB. Phytochemical Methods. London: Chapman and Hall Ltd; 1973.

15. Al-Rehaily AJ, Al-Said MS, Al-Yahya MA, Mossa JS, Rafatullah S. Ethnopharmacological studies on Allspice (Pimenta dioica) in laboratory animals. Pharm Biol 2002;40:200-5.

16. Lai PK, Roy J. Antimicrobial and chemopreventive properties of herbs and spices. Curr Med Chem 2004;11:1451-60.

17. Gochev VK, Girova TD. Antimicrobial activity of various essential oils against spoilage and pathogenic microorganisms isolated from meat products. Biotechnol 2009;23:900-4.

18. Zabka M, Pavela R, Slezakova L. Antifungal effect of Pimenta dioica essential oil against dangerous pathogenic and toxicogenic fungi. Ind Crops Prod 2009;30:250-3.

\section{How to cite this article}

Akhilesh Bhat, Raveesha KA. Antifungal activity of Pimenta dioica (L.) Merril an aromatic medicinal tree. Int J Pharm Pharm Sci 2016;8(10):92-95. 